3. Nguyễn Văn Sơn. Nghiên cứu đăc điểm hình ảnh đông cứng khớp vai và hiệu quả điều trị bằng bơm nong ổ khớp dưới hướng dẫn của xquang. Luận án tiến sỹ y học. 2011;

4. Tveitå EḰ, Tariq R, Sesseng $S$, Juel NG, Bautz-Holter E. Hydrodilatation, corticosteroids and adhesive capsulitis: a randomized controlled trial. BMC musculoskeletal disorders. 2008;9(1):1-10.

5. Yoon JP, Chung SW, Kim J-E, et al. Intraarticular injection, subacromial injection, and hydrodilatation for primary frozen shoulder: a randomized clinical trial. Journal of shoulder and elbow surgery. 2016;25(3):376-383.

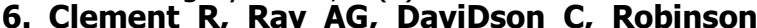
CM, PERks FJ. Frozen shoulder: long-term outcome following arthrographic distension. Acta Orthop Belg. 2013;79(4):368-7

7. Nguyễn Thi Bảo Thoa. Đánh giá hiệu quả cửa phương pháp tiêm nong khớp vai dưới hướng dân của siêu âm trong điều trị viêm quanh khớp vai thể đông cứng. Đại học y Hà nội; 2015.

\title{
KẾT QUẢ BƠM XI MĂNG QUA CUỐNG ĐIỀU TRI LÚN THÂN ĐỐT SỐNG NGƯ⿱C, THẮT LƯNG DO LOÃNG XƯƠNG TẠI BỆNH VIỆN THANH NHÀN
}

\section{TÓM TĂT}

Mục tiêu: Đánh giá kết quả bơm xi măng qua cuống điều trị lún thân đốt sống ngực, thắt lưng do loãng xương tại Bệnh viện Thanh Nhàn. Phương pháp: Thiết kế nghiên cứu mô tả trên 71 bệnh nhân. Kết quả: Biến chứng tràn xi măng trong mổ gồm có tỷ lệ bệnh nhân có tràn xi măng qua bờ trước thân đốt sống, có tràn vào đĩa đệm lần lượt là $16,9 \%$ và $11,3 \%$. Tỷ lệ ngấm xi măng trên $2 / 3$ đốt là $78,9 \%$. Có sự khác biệt có ý nghĩa thống kê $(p<0,001)$ giữa điểm VAS trung bình của bệnh nhân tại các thời điểm theo dõi. Tỷ lệ bệnh nhân đạt kết quả rất tốt và tốt sau bơm xi măng qua da lần lượt là $63,4 \%$ và $29,6 \%$. Kết luận: Bơm xi măng đốt sổng qua da là một phương pháp ít xâm lấn, hiệu quả điêuu trị cao với tỷ lệ biến chứng thấp và thường không để lại di chứng, giảm đau tốt và phục hồi vận động nhanh chóng. măng.

Tư khóa: Lún thẩn đổt sống, loãng xương, bơm xi

\section{SUMMARY}

THE RESULTS OF CEMENT INJECTION

THROUGH THEPEDICLE THAT TREAMENT OF

THORACO-LUMBAR VERTEBRAE COMPRESSION PATIENTS DUE TO OSTEOPOROSIS

\section{AT THANH NHAN HOSPITAL}

Objective: To evaluate the results of cement injection through the pedicle that treatment of thoracolumbar vertebrae compression patients due to

\section{${ }^{1}$ Bệnh viện Thanh Nhàn}

2Viện Chân thương Chỉnh Hinh, Bệnh viện Hưu nghi Việt Đức

${ }^{3}$ Trường Đại học Y Hà Nội

Chiu trách nhiệm chính: Nguyễn Lê Bảo Tiến

Email: bstiencsvd@gmail.com

Ngày nhận bài: 18.12.2020

Ngày phản biện khoa họ: 22.01.2021

Ngày duyệt bài: 1.2.2021
Hà Văn Lĩnh ${ }^{1}$, Nguyễn Lê Bảo Tiến ${ }^{2}$, Phan Minh Trung ${ }^{1}$, Võ Văn Thanh ${ }^{2,3}$

osteoporosis at Thanh Nhan Hospital. Methods: This is a descriptive study of 71 patients. Results: The symptoms in surgery were the percentage of patients who were $16.9 \%$ and $11.3 \%$, respectively. The percentage ofthe cement infiltration on $2 / 3$ vertebrae was $78.9 \%$. There was a statistically significant difference $(p<0.001)$ between the mean VAS score at the time. The percentage of patients with very good and good results after cement injectionthrough the skin were $63.4 \%$ and $29.6 \%$, respectively. Conclusion: The cement injection through the skin was a less invasive method, highly effective treatment with low symptom rate and this method hasn't leaved any sequelae, good pain relief, fast musculoskeletal system recovery.

Keywords: Vertebrae compression, osteoporosis, cement injection.

\section{I. ĐẶT VẤN ĐỀ}

Loãng xương là một rối loạn của hệ thống xương được đặc trưng bởi sự suy giảm sức bền của xương, dẫn tới làm tăng nguy cơ gãy xương[1]. Theo thống kê tại Mỹ có khoảng $700.000-1.000 .000$ trường hợp gãy xẹp thân đốt sống do loãng xương mỗi năm, với hơn $1 / 3$ trở thành đau mạn tính. Xẹp đốt sống xảy ra ở $25 \%$ bệnh nhân nữ trên 50 tuổi và $40 \%$ bên nhân từ $80-85$ tuổi. Do vậy xẹp đốt sống do loãng xương đang trở thành một vấn đề sức khỏe toàn câu, cần được quan tâm khi tuổi thọ của dân số thế giới ngày càng tăng lên.

Xẹp đốt sống là một trong những biến chứng "thầm lặng" ở những bệnh nhân bị loãng xương. Để điêu trị xẹp đốt sống do loãng xương thì có nhiều phương pháp. Tuy nhiên phần lớn các trường hợp xẹp đốt sống do loãng xương không đáp ứng với điều trị nội khoa, bệnh nhân vẫn có tình trạng đau lưng kéo dài, ảnh hưởng nhiều 
đến chất lượng cuộc sống, do vậy phương pháp tạo hình thân đốt sống qua da là một biện pháp thay thế hữu hiệu giúp bệnh nhân giảm đau nhanh, rút ngắn thời gian quay trở lại với công viêc và nâng cao chất lượng cuốc sống. Tao hình đốt sống qua da là phương pháp điêu trị mới, được áp dụng ngày càng nhiêu trong việc điều trị giảm đau cho những bệnh nhân bị xẹp đốt sống bệnh lý, trong đó có nguyên nhân do loãng xương, một lượng xi măng sinh học được bơm vào thân đốt sống qua kim chuyên dụng, xi măng sinh học giúp hàn gắn các gãy xương siêu nhỏ trong thân đốt sống, làm bền vững thân đốt sống và giảm đau nhanh cho người bệnh [2].

Do đó, chúng tôi tiến hành nghiên cứu đề tài này nhằm đánh giá kết quả bơm xi măng qua cuống điều trị lún thân đốt sống ngực, thắt lưng do loãng xương tại Bệnh viện Thanh Nhàn.

\section{II. ĐỐI TƯợNG VÀ PHƯƠNG PHÁP NGHIÊN CỨU}

2.1. Đối tượng nghiên cứu. Gồm 71 bệnh nhân được chẩn đoán lún thân đốt sống ngưc, thắt lưng do loãng xương và được điều trị tạo hình thân đốt sống bằng bơm xi măng.

* Tiêu chuẩn lựa chọn bệnh nhân trong nhóm nghiên cứu:

- Xẹp đốt sống ngực, thắt lưng do loãng xương (T-score $\leq-2,5$ ).

- Bệnh nhân bị xẹp một hay nhiều đốt sống do loãng xương, có triêuu chứng lâm sàng, không hay ít đáp ứng với điều trị nội khoa sau 3 tháng, trên MRI có hình ảnh phù tủy xương thân đốt sống.

\section{* Tiêu chuẩn loai trừ:}

- Bệnh nhân có các chống chỉ định điều trị tuyệt đối với can thiệp ngoại khoa nói chung: rối loạn đông máu, suy hô hấp, nhiễm khuẩn huyết.

Bệnh nhân bị xẹp đốt sống mức độ 3 theo Genant, xẹp đốt sống do chấn thương đơn thuần, không kèm theo các bệnh lí gây giảm mật độ xương.

Địa điểm nghiên cứu: khoa Chấn thương chỉnh hình Bệnh viện Thanh Nhàn.

Thời gian nghiên cứu: Từ tháng 01 năm 2019 tới tháng 12 năm 2019.

\subsection{Phương pháp nghiên cứu}

* Thiết kế nghiên cứu mô tả

* Xử Iý số liệu. Số liệu sau khi thu thập được làm sạch và nhập vào máy tính. Xử lý và phẩn tích số lieêu bằng phần mềm thống kê y học SPSS 16.0. Mức ý nghĩa thống kê alpha $<0,05$ được áp dụng.

\section{KẾT QUẢ NGHIÊN CứU}

\subsection{Biến chứng trong mổ và tỷ lệ ngấm}

xi măng của bệnh nhân

Bảng 3.1 Biến chứngtrong mổ và tỷ lệ ngấm xi măng

\begin{tabular}{|c|c|c|}
\hline & $\mathbf{n}$ & $\%$ \\
\hline \multicolumn{3}{|l|}{ Biến chứng } \\
\hline Tràn qua bờ trước thân đốt sống & 12 & 16,9 \\
\hline Tràn qua bờ sau đốt sống & 0 & 0 \\
\hline Tràn vào lô liên hợp & 0 & 0 \\
\hline Tràn vào đĩa đệm đốt sống & 8 & 11,3 \\
\hline $\begin{array}{c}\text { Tràn vào mạch máu trước } \\
\text { thân đốt sống }\end{array}$ & 3 & 4,2 \\
\hline \multicolumn{3}{|c|}{ Tỷ lệ ngấm xi măng trong thân đốt } \\
\hline Dưới $1 / 3$ & 3 & 4,2 \\
\hline Từ $1 / 3-2 / 3$ & 12 & 16,9 \\
\hline Trên $2 / 3$ & 56 & 78,9 \\
\hline
\end{tabular}

Tỷ lê biến chứng tràn xi măng trong mố: $16,9 \%$ bệnh nhân có tràn xi măng qua bờ trước thân đốt sống, $11,3 \%$ tràn vào đĩa đệm. Có $4,2 \%$ là tỷ lệ bệnh nhân có biến chứng tràn xi măng vào mạch máu trước thân đốt sống, nhưng tất cả các bệnh nhân này đều không có biểu hiện triệu chứng trên lâm sàng(Bảng3.1).

Đa số lượng cement bơm vào mỗi đốt sống đều ngấm khá cao. Tỷ lệ ngấm trên $2 / 3$ đốt là $78,9 \%$. Từ $1 / 3-2 / 3$ là $16,9 \%$, và $4,2 \%$ ngấm dưới $1 / 3$ đốt sông.

3.2. Phân bố bệnh nhân theo thang điểm VAS sau bơm xi măng

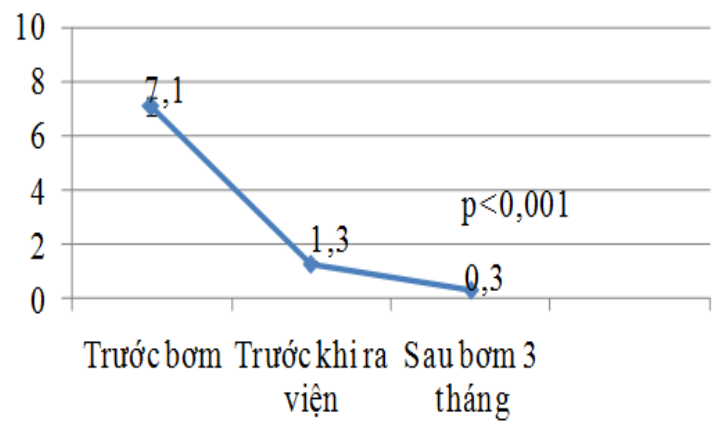

Biểu đồ 3.1. Diễn biến điểm VAS trung bình theo thời gian

Có sự khác biệt có ý nghĩa thống kê $(p<0,001)$ giữa điểm VAS trung bình của bệnh nhân tại các thời điểm theo dõi. Trước bơm điểm VAS trung bình là $7,1 \pm 1,6$; Trước khi ra viện điểm VAS trung bình là $1,3 \pm 1,2$; sau bơm 3 tháng điểm VAS trung bình giảm xuống $0,3 \pm$ 0,2. (Biểu đồ 3.1).

3.3. Phân bố bệnh nhân theo thang điểm MacNab sau bớm xi măng 
Bảng 3.2. Phân bố bệnh nhân theo thang điểm MacNab sau bơm 3 tháng

\begin{tabular}{|c|c|c|c|}
\hline$\%$ & $\mathbf{n}$ & Đánh giá & \\
\hline 63,4 & 45 & Rất tốt & Không đau, không hạn chế vận động, công việc. \\
\hline 29,6 & 21 & Tốt & $\begin{array}{l}\text { Không bị đau lưng hoắc đau chân thường xuyên, còn ảnh hưởng đến } \\
\text { khă năng làm việc bình thường hoặc các hoạt động giải trí. }\end{array}$ \\
\hline 7,0 & 5 & $\begin{array}{l}\text { Trung } \\
\text { bình }\end{array}$ & $\begin{array}{c}\text { Cải thiện một phân chức năng nhưng còn đau dữ dội từng cơn khiến } \\
\text { bệnh nhân phải rút ngắn hoặc giảm bớt công việc cũ̃ng như các hoạt } \\
\text { động giải trí khác. }\end{array}$ \\
\hline 0 & 0 & Xấu & $\begin{array}{l}\text { Không hoặc ít cải thiện tình trạng đau của bệnh nhân, có thế mức độ } \\
\text { đauu còn tăng lên, thậm chí đòi hỏi sự can thiệp phẫu thuật. }\end{array}$ \\
\hline 100 & 71 & & Tổng \\
\hline
\end{tabular}

$100 \%$ bệnh nhân trong nghiên cứu đều đạt kết quả tốt sau bơm xi măng qua da trong đó $63,4 \%$ đạt kết quả rất tốt và 29,6\% đạt kết quả tốt, 7,0\% bệnh nhân đạt kết quả trung bình (Bảng 3.2).

\section{BÀN LUÂ̂N}

4.1. Biến chứng trong mổ và tỷ lệ ngấm xi măng của bệnh nhân. Để phòng tránh các tai biến xảy ra trong quá trình bơm xi măng cần kiểm tra liên tục dưới màn huỳnh quang tăng sáng. Kết quả nghiên cứu của chúng ta cho thấy trong nghiên cứu của chúng tôi có gặp các biến chứng sau: $16,9 \%$ bệnh nhân có tràn xi măng qua bờ trước thân đốt sống, $11,3 \%$ tràn vào đĩa đệm liền kề và có $4,2 \%$ có tràn xi măng vào mạch máu quang thân đốt sống. Theo Đào Văn Nhân năm 2012, biến chứng thường gặp là xi măng rò vào đĩa đệm và rò ra cạnh sống chiếm $18,5 \%$ [3]. Nghiên cứu của Đàm Thủy Trang năm 2013 trong 18 lần thực hiện tạo hình đốt sống qua da, có 4 trường hợp tràn xi măng vào đĩa đệm gian đốt sống, 01 trường hợp tràn xi măng vào tînh mạch ngoài màng cứng[4]. Như vậy, tỷ lệ xi măng tràn ra đĩa đệm và xung quanh đốt sống còn khá cao.

Để đánh giá mức độ ngấm xi măng trong thân đốt sống chúng tổi dựa vào hình ảnh $X$ quang cột sống sau bơm xi măng qua da: Tỷ lệ ngấm trền $2 / 3$ đốt là $78,9 \%$, từ $1 / 3-2 / 3$ là $16,9 \%$, và 4,2\% ngấm dưới $1 / 3$ đốt sống, tương tự kết quả nghiên cứu của Phạm Mạnh Cường [5]. Như vậy lượng xi măng bơm vào đốt sống phụ thuộc chủ yếu vào nguyên nhân gây $X Đ S$ và mức độ tổn thương. Do đó, việc nghiên cứu kỹ hình ảnh đốt sống bị xẹp trước bơm sẽ giúp lên kế hoạch cho hướng chọc kim vào đúng ổ tiêu xương, tránh các đường võ̃ xương, để phòng các biến chứng. Việc trộn xi măng đúng kỹ thuật sẽ đảm bảo độ nhớt của xi măng và giúp an toàn khi bơm.

4.2. Đánh giá bệnh nhân sau bơm xi măng bằng thang điểm VAS. Trong nghiên cứu của chúng tôi, các bệnh nhân đều được thăm khám định kỳ sau bơm 1,3 tháng. 100\% bệnh nhân đều giảm đau ngay sau bơm xi măng.
Điểm VAS trung bình trước khi ra viện là $1,3 \pm$ 1,2 và sau bơm 3 tháng là $0,3 \pm 0,2 ;$ khi đem so sánh với điểm VAS trung bình trước bơm xi măng $7,1 \pm 1,6$, sự khác biệt có ý nghĩa thống kê với $\mathrm{p}<0,001$. Tương tự nghiên cứu của các Trịnh Văn Cường [6] và Jung-Hoon Lee [7]. Điêu này phản ánh hiệu quả điều trị của phương pháp là rất cao trong việc giảm đau cho bệnh nhân sau bơm xi măng.

4.3. Đánh giá bệnh nhân sau bơm xi măng bằng thang điểm MacNab. Để đánh giá hiệu quả tạo hình đốt sống qua da chúng tôi sử dụng thang điểm MacNab. Kết quả cho thấy $63,4 \%$ bệnh nhân đạt rất tốt, 29,6\% đạt tốt, $7,0 \%$ đạt trung bình và không có bệnh nhẩn nào đạt kết quả xấu sau bơm xi măng 3 tháng. Tương tự với kết quả nghiên cứu của Trịnh Văn Cường bơm xi măng cho 41 bệnh nhân với kết quả tỷ lệ kết quả khá và tốt là $87,8 \%$, và tỷ lệ kết quả trung bình là 12,2\% [6].

\section{KẾT LUẬN}

Bơm xi măng đốt sống qua da là một phương pháp ít xâm lấn, hiệu quả điều trị cao với tỷ lệ biến chứng thấp và thường khồng để lại di chứng, giảm đau tốt và phục hồi vận động nhanh chóng.

\section{TÀI LIÊU THAM KHẢO}

1. Klibanski, A., et al., Osteoporosis prevention, diagnosis, and therapy. Journal of the American Medical Association, 2001. 285(6): p. 785-795.

2. Lad, S.P., et al., Trends in pathological vertebral fractures in the United States: 1993 to 2004 Journal of Neurosurgery: Spine, 2007. 7(3): p. 305-310.

3. Đào Văn Nhân, Đánh giá kết quả bước đâu tạo hình thân đốt sông qua da bằng bơm cement sinh học ở bệnh nhân gãy xep đốt sống do loãng xương. Y học thành phổ Hồ Chí Minh, 2012. 16(4): p. 330-334.

4. Đàm Thuỷ Trang, Nghiên cứu hiệu quả của phương pháp tạo hình đốt sống qua da trong điều trị xẹp đốt sống mới do loãng xương. Luận văn tốt nghiệp Bác Sĩ Nội Trú, 2013. 
5. Phạm Mạnh Cường and Phạm Minh Thông, Đánh giá hiệu quả của phương pháp tạo hình đốt sống qua da trong điều trị xẹp đốt sống bệnh lý. Kỷ yêu các công trình nghiên cứu khoa học Bệnh viện Bach Mai, 2008. 1: p. 62-68.

6. Trinh Văn Cường and Nguyễn Quốc Bảo, Đăc điểm lâm sàng, cận lâm sàng và kết quả điều trị xẹp đốt sống do loãng xương bằng bơm cement sinh hoc qua cuống. Y Hoc Thành Phố Hồ Chí Minh, 2017. 21(6): p. 213-217.

7. Lee, J.-H., et al., Segmental deformity correction after balloon kyphoplasty in the osteoporotic vertebral compression fracture. Journal of Korean Neurosurgical Society, 2007. 42(5): p. 371.

\title{
VAI TRÒ CỦA CÁC CAN THIÊP ÍT XÂM LẤN TRONG ĐIỀU TRI BẢO TỒN KHÔNG MỔ CHẤN THƯƠNG THẬN
}

\author{
Ngô Trung Kiên' ${ }^{1}$ Hoàng Long ${ }^{2}$, Nguyễn Phú Việt ${ }^{3}$
}

TÓM TẮT

Mục tiêu: đánh giá vai trò của các biện pháp can thiệp ít xâm lấn trong điều trị bảo tồn không mổ chấn thương thân. Đối tượng và phương pháp: nghiên cứu tiến cứu các trướng hợp chấn thương thận được điều tri bảo tồn không mố tại bênh viên Việt Đức từ năm 2013 đến 2018. Kết quả: 24 bệnh nhân can thiệp mạch, trong đó 13 trường hợp được chỉ định từ đâu do có tổn thương mach máu thân biểu hiên chảy máu thể hoạt động, 11 bệnh nhân được chỉ định trong quá trình theo dỗi điều trị do giả phình động mạch thận. 13 trường hợp nội soi tiết niệu đặt thông jj, trong đó 8 trường hợp chỉ định từ đầu, 5 trường hợp chỉ định trong quá trình theo dõi điêuu trị do thoát nước tiểu dai dằng hoặc máu cục trong bể thận. Kết luâan: các biện pháp can thiêp ít xâm lấn xử lý được các tổn thương trong chấn thương thận mà trước đẩy thường phải phẫu thuât, do đó làn tăng tỷ lệ thành công của điều trị bảo tồn không mổ.

Tư khóa: chấn thương thận, can thiệp mach, nội soi tiết niệu.

\section{SUMMARY}

\section{THE ROLE OF MINI INVASIVE}

\section{INTERVENTION IN NON OPERATIVE}

MANAGEMENT IN RENAL TRAUMA

Objectives: to evaluate the role of less invasive interventions in conservative treatment without renal trauma surgery. Subjects and methods: a prospective study of non-operative management renal trauma cases at Viet Duc Hospital from 2013 to 2018. Results: 24 patients with vascular interventions, of which 13 were initially indicated due to renal vascular lesions that expressed active bleeding, 11 were assigned during follow-up treatment because of renal artery aneurysm. 13 cases of urological endoscopy, in which 8 cases indicated from the beginning, 5 cases

${ }^{1}$ Bênh viên Xanh Pôn

${ }^{2}$ Đại học Y Hà Nội

${ }^{3}$ Học viện Quân Y

Chịu trách nhiệm chính: Ngô Trung Kiên

Email: kienngotrung.knt@gmail

Ngày nhận bài: 17.12.2020

Ngày phản biên khoa họ: 26.01.2021

Ngày duyệt bài: 3.2.2021 indicated during treatment monitoring due to persistent urinary extravasation or blood clots in the renal pelvis. Conclusion: Less invasive interventions address lesions in renal trauma that used to be surgical, thus increasing the success rate of nonoperative management.

Keywords; renal trauma, vascular intervention, urinary endoscopy.

\section{I. ĐĂT VẤN ĐỀ}

Chấn thương thận hay gặp nhất trong chấn thương đường tiết niệu, chiếm tỷ lệ khoảng $10 \%$ chấn thương bụng kín và khoảng 1-5\% các chấn thương nói chung. Nguyên nhân chủ yếu là tai nạn giao thông chiếm tới 65,5\% - 87,5\%[1].

Trước đây, CTT chủ yếu được chỉ định mổ cấp cứu giống như chấn thương các tạng đặc khác nhưng tỷ lệ phải cắt bỏ thận rất cao, có thể có những biến chứng, di chứng hoăc đôi khi là một can thiệp không cân thiết vì tổn thương đã tự cầm máu.

Trong khoảng 3 thập kỷ trở lại đây, nhờ sự phát triển của chẩn đoán hình ảnh, đặc biệt là chụp cắt lớp vi tính đa dãy (MSCT - multi slide computed tomography) $)_{\ell}$ việc đánh giá và phân loại thương tổn giải phâuu trong CTT được chính xác hơn, tạo cơ sở để quyết định các phương pháp điều trị thích hợp. Bên cạnh đó, những tiến bộ của y học trong nhiêuu lĩnh vực được áp dụng trong quá trình điều trị, theo dõi và xử trí các biến chứng của CTT đã làm cho tỷ lệ thành công của điều trị bảo tôn không mổ tăng lên. Đó là điện quang can thiệp (Interventional Radiology), nút mạch chọn lọc với các trường hợp CTT chảy máu nhiêu từ nhánh động mạch bị tổn thương hoặc nút giả phình mạch hình thành sau CTT. Với các khối máu tụ, nước tiểu, có thể dẫn lưu qua da kết hợp với đặt thông jj niệu quản - bể thận qua nội soi tiết niệu (Endourological) [5].

Việc áp dụng MSCT và các biện pháp can thiệp ít xâm lấn trong chẩn đoán và điêu trị chấn thương thân đã làm cho phương pháp điều trị bảo tồn không mổ (NOM) trở thành lựa chọn 